\title{
Proposta de atividade interdisciplinar para o estudo das línguas portuguesa e inglesa: uma experiência mediada pela pesquisa no mestrado profissional para professores
}

\section{Proposal of interdisciplinarity activity for the study of the portuguese and english languages: a mediated research experience in the professional ma for teachers}

\author{
Wagner Rodrigues Silva* \\ Universidade Federal do Tocantins \\ Palmas, Tocantins, Brasil \\ Andréia Francisca de Moura** \\ Universidade Federal do Tocantins \\ Palmas, Tocantins, Brasil \\ Aline Barbosa Rodrigues*** \\ Universidade Federal do Tocantins \\ Palmas, Tocantins, Brasil \\ Lívia Chaves de Melo**** \\ Universidade Federal do Tocantins \\ Palmas, Tocantins, Brasil
}

\begin{abstract}
Resumo: Neste artigo, apresentamos o resultado de uma investigação desenvolvida com professores matriculados em um mestrado profissional para educadores e responsáveis pelo ensino de Língua Portuguesa, em escolas públicas brasileiras de ensino básico. Analisamos como os referidos profissionais compreendem os processos de alfabetização e de letramento, além de lidarem com essas noções teóricas no próprio local de trabalho. Analisamos ainda uma diretriz curricular em fase de aprovação pelo governo brasileiro, a qual regulamentará os conteúdos disciplinares e habilidades a serem trabalhados em cada etapa do ensino básico. Ao final do artigo, compartilhamos uma atividade pedagógica de análise linguística, considerando a Língua Portuguesa e a Língua Inglesa como disciplinas catalisadoras de conteúdos e saberes diversos. A atividade se configura como uma resposta aos desafios identificados nos dizeres das professoras e da diretriz curricular focalizada.
\end{abstract}

Palavras-chave: Formação de professores. Interdisciplinaridade. Material didático.

* Doutor a Linguística Aplicad Bolsista de Produtividade do CNPq e professor da Universiuade Federal do Tocantins JFT).Email:wagnerodriguesilva@gmail.com.

** Aluna do Programa de Mestr uo Profissional em Letras (ProfLetras), Universidade Federal do Tocantins (UFT). Email: andyluzmoura@hotmail.com.

***Aluna do Mestrado Profissional em Letras (ProfLetras), Universidade Federal do Tocantins (UFT). Email: alinebro1@live.com.

****Doutora em Letras: Ensino de Língua e Literatura, Professora da Universidade Federal do Tocantins (UFT), Campus Universitário de Porto Nacional. Email: liviachavesmelo@hotmail.com. 


\begin{abstract}
In this paper, we present the results of an investigation developed with teachers enrolled at the professional master's degree for educators who are responsible for teaching Portuguese Language in Brazilian public schools of basic education. We analyzed how these professionals understand the processes of alphabetization and literacy and deal with these theoretical notions in the workplace. We also analyzed a proposed official document currently being approved by the Brazilian government which will regulate disciplinary contents and skills to be worked in each stage of basic education. At the end of this article, we shared a pedagogical activity of linguistic analysis, considering the Portuguese Language and English Language as catalyst disciplines of diverse contents and knowledges. The activity is configured as a response to the challenges identified in the teachers' statements and the focused official document.
\end{abstract}

Keywords: Teacher education. Interdisciplinarity. Didactic_material.

\title{
1 INTRODUÇÃO
}

Neste artigo, investigamos algumas percepções em torno do ensino do português como língua materna, compartilhadas por professoras matriculadas em uma das unidades da rede nacional que compõe o Mestrado Profissional em Letras (ProfLetras) ${ }^{1}$. Focalizamos, mais diretamente, como as professoras: (1) compreendem o processo de alfabetização e de letramento dos alunos do Ensino Fundamental II e Ensino Médio; e (2) apreendem algumas contribuições teóricas, em torno dos processos mencionados, para o ensino do português como língua materna, nas escolas públicas a que estão vinculadas ${ }^{2}$.

Esta pesquisa foi realizada a partir da investigação científica de produções escritas elaboradas pelas próprias professoras, na disciplina Alfabetização e Letramento, ministrada no referido mestrado profissional. A atividade de ensino e pesquisa na disciplina citada foi descrita em Silva, Sousa e Araújo (2017) e Silva, Guimarães e Medeiros (2018). O exame dos escritos docentes foi realizado pelas próprias professoras, nas aulas da disciplina focalizada, bem como uma investigação da Base Nacional Comum Curricular - BNCC (BRASIL, 2017). Neste artigo, retomamos apenas o estudo da proposta para o ensino de Língua Portuguesa e de Língua Inglesa, na BNCC (BRASIL, 2017).

Esta pesquisa está situada no campo indisciplinar da Linguística Aplicada. Como referenciais, utilizamo-nos de algumas abordagens da alfabetização e do letramento (cf. BARTON; HAMILTON, 2012; KLEIMAN, 1995; 2006; SOARES, 2004; 2016; STREET, 2014). Problematizamos questões pertinentes ao ensino da Língua Portuguesa e da Língua Inglesa, considerando alguns papéis exercidos pela escola e disciplinas curriculares (cf. KOMESU e TENANI, 2009; LUCK, 1994). Os referenciais teóricos são mobilizados ao longo deste texto, não havendo uma seção dedicada à revisão da literatura científica de referência.

\footnotetext{
${ }^{1}$ Este trabalho contribui para as investigações científicas desenvolvidas no grupo de pesquisa Práticas de Linguagens - PLES (UFT/CNPq).

${ }^{2}$ Neste artigo, optamos por utilizar o gênero feminino para fazer referência à turma do Profletras, uma vez que as professoras eram a grande maioria, assim como acontece nas escolas brasileiras: treze (13) professoras e dois (02) professores. Assim nos contrapomos à prescrição gramatical da língua portuguesa no tocante à concordância de gênero.
} 
Além desta Introdução, das Considerações Finais e das Referências, este artigo está organizado em três principais seções: Análise dos escritos docentes; Proposta pedagógica para o ensino de língua na BNCC; e Proposta de atividade pedagógica. Nessa última seção, compartilhamos uma atividade didática de análise linguística, considerando as disciplinas de Língua Portuguesa e a Língua Inglesa como catalisadoras de conteúdos e saberes diversos.

\section{ANÁLISE DOS ESCRITOS DOCENTES}

As produções escritas investigadas neste artigo correspondem a textos configurados entre os gêneros 'relato de experiência' e 'ensaio acadêmico', produzidos por professoras. Foram solicitados em uma atividade diagnóstica implementada por correio eletrônico, antes das aulas presenciais da disciplina Alfabetização e Letramento, ministrada no ProfLetras (cf. SILVA; SOUSA; ARAÚJO, 2017; SILVA; GUIMARÃES; MEDEIROS, no prelo).

A atividade foi proposta para verificar como as abordagens da Alfabetização e do Letramento eram mobilizadas em aulas de Língua Portuguesa, nas escolas públicas de ensino básico em que atuavam as professoras matriculadas no mestrado profissional. Reproduzimos adiante o enunciado da atividade proposta. As professoras foram orientadas a responderem aos questionamentos da atividade sem consultar a fontes bibliográficas.

Exemplo 1: Enunciado da Atividade Escrita
Considerando sua formação e experiência profissional em sala de aula ou outros contextos de
formação, como você compreende alfabetização e letramento? Quais são os
prováveis/possíveis desdobramentos desses conceitos para sua prática profissional? Há
demandas no seu local de trabalho para as quais os referidos conceitos precisem ser
mobilizados?

Para a análise de conteúdo das produções escritas, concebemos a alfabetização como o processo de aprendizagem do sistema notacional alfabético e ortográfico da língua portuguesa. Conforme Soares (2016, p. 38), as abordagens da alfabetização e do letramento podem ser caracterizadas por três facetas da língua(gem) interdependentes. Essas facetas, sintetizadas no Quadro 1, agrupam os componentes do processo de aprendizagem da escrita em aulas de Língua Portuguesa.

\begin{tabular}{c|c}
\hline \multicolumn{2}{c}{ ALFABETIZAÇÃO } \\
\hline $\begin{array}{c}\text { FACETA } \\
\text { LINGUÍSTICA }\end{array}$ & $\begin{array}{l}\text { "o objeto de conhecimento é essencialmente linguístico - o sistema } \\
\text { alfabético-ortográfico de escrita". }\end{array}$ \\
\hline \multicolumn{1}{c}{ LETRAMENTO } \\
\hline $\begin{array}{c}\text { FACETE } \\
\text { INTERATIVA }\end{array}$ & $\begin{array}{l}\text { "o objeto de conhecimento é o uso da língua escrita para a interação - } \\
\text { a compreensão e a produção de textos, o que envolve, para além da }\end{array}$ \\
\hline
\end{tabular}




\begin{tabular}{c|l}
\hline & $\begin{array}{l}\text { dimensão linguística, elementos textuais e pragmáticos, não } \\
\text { exclusivamente linguísticos". }\end{array}$ \\
\hline FACETA & $\begin{array}{l}\text { "o objeto do conhecimento são os usos e as funções da língua escrita } \\
\text { em diferentes contextos sociais e culturais e em diferentes eventos de } \\
\text { letramento, estando presentes, portanto, inúmeros elementos não } \\
\text { linguísticos". }\end{array}$ \\
\hline & \multicolumn{1}{c}{ Quadro 1: Facetas da Língua(gem) } \\
Fonte: Soares (2016, p. 38)
\end{tabular}

Os conhecimentos inerentes às facetas compartilhadas se constroem em meio a práticas de interação social mediadas por usos da escrita, as quais se constituem em "eventos de letramento"3. Por letramento, compreendemos, de acordo com Kleiman (1995, p. 19), "um conjunto de práticas sociais que usam a escrita, enquanto sistema simbólico e enquanto tecnologia, em contextos específicos, para objetivos específicos". Nesse sentido, destacamos a relevância do trabalho com a alfabetização, caracterizada pela faceta linguística da língua(gem), contextualizado em produtivas situações interativas informadas pelo letramento.

É imprescindível a mobilização das abordagens pedagógicas da alfabetização e do letramento no processo de aprendizado da leitura e da escrita. Uma criança alfabetizada e letrada é aquela que não só lê e escreve em resposta às atividades pedagógicas propostas na escola, mas também domina habilidades de leitura e escrita necessárias para a participação em eventos de letramentos instaurados além das fronteiras da escola. Nessa perspectiva, concordamos com Soares (2004, p. 14), ao afirmar que

Dissociar alfabetização e letramento é um equívoco porque, no quadro das atuais concepções
psicológicas, linguísticas e psicolinguísticas de leitura e escrita, a entrada da criança (e também
do adulto analfabeto) no mundo da escrita ocorre simultaneamente por esses dois processos:
pela aquisição do sistema convencional de escrita - a alfabetizaçãa - e pelo desenvolvimento
de habilidades de uso desse sistema em atividades de leitura e escrita, nas práticas sociais que
envolvem a língua escrita - o letramento (itálico do original).

Inicialmente, observamos algumas noções de alfabetização e de letramento explicitadas nos escritos docentes: (1) alfabetização como aprendizagem da leitura e da escrita - processo de aquisição dos conhecimentos linguísticos necessários à aprendizagem da leitura e da escrita; (2) letramento e alfabetização como sinônimos alfabetização e letramento associados ao mesmo conceito, não esclarecendo alguma distinção entre os fenômenos; (3) alfabetização como atividade desencadeadora de saberes necessários para o letramento - alfabetização como sendo requisito para o letramento.

\footnotetext{
${ }^{3}$ De acordo com Barton e Hamilton (2012, p. 7), "eventos de letramento são atividades em que a escrita exerce um papel. Usualmente, há um texto escrito, ou textos, no centro da atividade, onde pessoas interagem em torno do texto. Os eventos são episódios observáveis que emergem das práticas e são moldados por elas".
} 
Das 16 (dezesseis) professoras, 12 (doze) compartilharam uma concepção de alfabetização alinhada ao que enuncia Soares (2016, p. 16): "um conjunto de procedimentos que, fundamentados em teorias e princípios, orientem a aprendizagem inicial da leitura e da escrita". Por outro lado, 02 (duas) professoras confundiram os fenômenos da alfabetização e do letramento, concebendo-os como similares. Houve ainda 02 (duas) professoras que consideraram a alfabetização como pré-requisito para o letramento, assim, entenderam o letramento como uma extensão ou consequência da alfabetização.

A maioria das professoras apontou a leitura e a escrita como principais demandas em seus contextos de trabalho. Organizamos essas demandas em duas categorias interconectadas: (1) demandas provocadas pelos alunos; e (2) demandas provocadas pelas instituições. As primeiras correspondem às necessidades que os alunos apresentam no processo de ensino aprendizagem. A leitura e a escrita são as habilidades que os alunos demonstram ter maior dificuldade, conforme os escritos das professoras. Houve 01 (um) caso em que a professora acrescentou o trabalho pedagógico com a oralidade como demanda dos alunos.

As segundas demandas correspondem às ações propostas pelas escolas, visando atender às necessidades discentes. Tais demandas, quase sempre, restringem-se a projetos pontuais, desenvolvidos pelas professoras de Língua Portuguesa. Para um melhor esclarecimento, essas demandas podem ser divididas em duas subcategorias correlacionadas: (1) provocadas pela escola; e (2) provocadas pela professora. Às vezes, a escola restringe o trabalho do professor, não colaborando com o profissional, preocupando-se mais com a burocracia institucional do que com a aprendizagem discente. Por outro lado, houve professoras que caracterizaram algumas colegas de trabalho como principais responsáveis pelo insucesso de alguns projetos de alfabetização. Há, portanto, professoras com insuficientes saberes para desenvolver projetos de alfabetização com resultados satisfatórios.

Em relação aos desdobramentos, a análise revela um incômodo das professoras no sentido de desenvolver práticas voltadas para a leitura e escrita. Muitas das atividades propostas pelas profissionais ainda não surtem o efeito necessário para suprir as demandas verificadas. Algumas professoras apontaram a formação continuada dos docentes e a interdisciplinaridade como fatores importantes para a melhoria do ensino de leitura e escrita. Isso pode ser observado no excerto do Exemplo 02, correspondente ao parágrafo final do relato escrito entregue por uma professora. O referido parágrafo se configura como um encaminhamento ou um tipo de proposição da profissional, diante dos desafios enfrentados no trabalho pedagógico pela comunidade escolar. Os excertos exemplificados neste artigo foram reproduzidos literalmente a partir dos escritos tomados como corpus desta investigação.

Exemplo 02: Relato Escrito

Precisamos concordar que os caminhos a seguir para desenvolver práticas de letramento para combater os problemas de leitura existentes devem ser aqueles que busquem reforço nos 
livros/textos, bibliotecas - sejam impressos, virtuais, impressos, em aplicativos de celulares e tablets, havendo possibilidade, etc.; - e no trabalho interdisciplinar entre os profissionais que atuam na unidade escolar. (Professora A)

Identificamos ainda críticas aos programas educacionais de alfabetização e de letramento, nos quais são feitos altos investimentos financeiros, aliados à dedicação das professoras. Porém, os resultados negativos têm causado inquietações. Com isso, alguns profissionais da educação são impulsionados a pesquisar e estudar, objetivando encontrar possíveis soluções para os problemas emergentes no seu respectivo local de trabalho.

No tocante aos desdobramentos ou contribuições dos estudos de alfabetização e de letramento nas escolas, organizamos os escritos docentes em três categorias: (1) aqueles em que há registros de intervenções para as demandas escolares (06 textos); (2) aqueles em que há registro de intervenções e que os responsáveis pelas atividades demonstram satisfação com os resultados (02 textos); (3) aqueles em que há registros do desenvolvimento de intervenções, apesar de os resultados serem considerados insuficientes (08 textos).

No excerto do Exemplo 3, ilustramos um tipo de intervenção produtiva realizada na escola em função do baixo desempenho discente. Trata-se do trabalho de planejamento pedagógico coletivo e interdisciplinar, em função do desenvolvimento da competência leitora dos alunos, daí a escolha da primeira pessoa do plural no relato escrito. O referido excerto está inserido na seção do relato intitulada "QUAIS SÃO OS PROVÁVEIS/POSSÍVEIS DESDOBRAMENTOS DESSES CONCEITOS PARA MINHA PRÁTICA PROFISSIONAL?”, que retoma diretamente o enunciado da atividade desencadeadora dos escritos integrantes do corpus desta investigação.

\begin{tabular}{l} 
Exemplo 3: Relato Escrito \\
\hline Por meio de ações interdisciplinares, buscamos conduzir os estudantes ao alcance da \\
competência leitora. [...] Ler mais para motivarmos nossos alunos a adquirirem o mesmo hábito. \\
Assim, os dias pedagógicos e os planejamentos por área são dedicados à seleção de material e \\
discussão sobre estratégias a serem empregadas nas aulas. Também trocamos experiências \\
sobre a aplicação dos planejamentos. Há ainda o fortalecimento da ação conjunta em prol do \\
letramento dos discentes, representado pela dedicação e inovação dos funcionários da \\
Biblioteca escolar, os quais desenvolvem projetos de incentivo à leitura (Professora B).
\end{tabular}

Grande parte das professoras participantes da pesquisa pontua alguma resposta para as demandas da formação de alunos leitores e escritores. Elas reconhecem que o esforço para familiarização dos alunos com distintas práticas de leitura e de escrita perpassa todas as disciplinas escolares. Em outros termos, essas práticas precisam ser trabalhadas pelas professoras desses componentes curriculares, conforme dito nos Exemplos 2 e 3.

As mudanças no ensino de Língua Portuguesa parecem não acompanhar o desenvolvimento das teorias linguísticas de referência, a exemplo dos avanços produzidos na Linguística Textual (cf. PAULIOKONIS; MARQUESI; ELIAS, 2017). De forma ingênua, essas teorias, muitas vezes, são apresentadas como respostas exclusivas para 
algumas demandas pedagógicas, ignorando contribuições teóricas necessárias e produzidas em outras disciplinas ou áreas do conhecimento. As inovações precisam ser instauradas nas aulas de língua, podendo resultar no empoderamento discente, permitindo-o participar de forma mais significativa das interações sociais mediadas por diferentes linguagens.

Também como resposta às demandas mencionadas, o Governo Federal brasileiro vem elaborando a BNCC (BRASIL, 2017), documento de caráter normativo definidor do conjunto de "objetos do conhecimento" a serem trabalhados em todas as escolas brasileiras de ensino básico. A seleção e a forma de exposição dos conteúdos disciplinares propostos para cada ano da escolarização, certamente, são os aspectos mais criticáveis no documento, conforme parcialmente investigado por Silva, Guimarães e Medeiros (no prelo). Os esclarecimentos ou orientações gerais se apresentam de maneira mais produtiva: a BNCC (2017) propõe a aprendizagem como desenvolvimento global, a superação da fragmentação disciplinar e a formação da autonomia discente; estimula o aproveitamento dos conteúdos escolares no cotidiano do aluno; e destaca a importância do contexto para dar sentido ao que é trabalhado na escola. Sobre parte desse documento, debruçamo-nos na seção seguinte.

\section{PROPOSTA PEDAGÓGICA PARA O ENSINO DE LÍNGUA NA BNCC}

A BNCC (BRASIL, 2017) protagoniza o ensino da Língua Portuguesa, pautado na reflexão, na ação e na interação dos aprendizes. No documento, são destacados os usos contextualizados da linguagem, a exemplo de práticas sociais envolvendo a oralidade, leitura e escrita.

Exemplo 4: BNCC - "Os conteúdos curriculares a serviço do desenvolvimento de competências"

"Assim, os objetivos de aprendizagem dos componentes curriculares estabelecidos pela BNCC para toda a Educação Básica visam à aprendizagem e ao desenvolvimento global do aluno. A superação da fragmentação radicalmente disciplinar do conhecimento, o estímulo à sua aplicação na vida real, o protagonismo do aluno em sua aprendizagem e a importância do contexto para dar sentido ao que se aprende são alguns dos princípios subjacentes à BNCC" (BRASIL, 2017, p. 17).

Exemplo 5: BNCC - "Língua Portuguesa"

"O objetivo norteador da BNCC de Língua Portuguesa é garantir a todos os alunos o acesso aos saberes linguísticos necessários para a participação social e o exercício da cidadania, pois é por meio da língua que o ser humano pensa, comunica-se, tem acesso à informação, expressa e defende pontos de vista, partilha ou constrói visões de mundo e produz conhecimento" (BRASIL, 2017, p. 63).

$\mathrm{Na}$ parte que concerne ao Ensino Fundamental ( $1^{\circ}$ ao $9^{\circ}$ ano), a BNCC (BRASIL, 2017) foi estruturada em competências específicas para cada área do conhecimento (Linguagens, Matemática, Ciências da Natureza e Ciências Humanas) e para cada 
componente curricular (Língua Portuguesa, Educação Física, Arte, Língua Inglesa, Matemática, Ciências, História, Geografia). São traçadas também habilidades relacionadas aos "objetos de aprendizagem", divididas em eixos organizadores. O componente curricular Língua Portuguesa, por exemplo, está organizado em cinco eixos descritivos: "oralidade"; "leitura"; "escrita"; "conhecimentos linguísticos e gramaticais"; e "educação literária" (cf. SILVA; GUIMARÃES; MEDEIROS, no prelo).

Os encaminhamentos para o trabalho com Língua Portuguesa enfatizam a importância do conhecimento da língua, do letramento e das habilidades que capacitarão os alunos para os papéis assumidos na sociedade em que estão inseridos. É necessário compreender que o ensino de língua depende em grande parte da mobilização de saberes em condições efetivas de uso, para que o aprendiz alcance avanços partindo dos conhecimentos possuídos.

A BNCC (BRASIL, 2017) parte do princípio de que os textos são elaborados com propósitos específicos e, por isso, os alunos devem ser preparados para questionar o texto, desenvolvendo, assim, o letramento crítico. Conforme dito no excerto reproduzido no Exemplo 6, o objetivo da aula de Língua Portuguesa é possibilitar a formação de alunos capazes de produzir sentidos para os textos materializados a partir de diferentes linguagens, além de produzir textos com linguagens diversas em resposta aos enunciados que lhes afetam.

Exemplo 6: BNCC - "Língua Portuguesa"

"A meta do trabalho com a Língua Portuguesa, ao longo do Ensino Fundamental, é a de que crianças, adolescentes, jovens e adultos aprendam a ler e desenvolvam a escuta, construindo sentidos coerentes para textos orais e escritos; a escrever e a falar, produzindo textos adequados a situações de interação diversas; a apropriar-se de conhecimentos e recursos linguísticos textuais, discursivos, expressivos e estéticos - que contribuam para o uso adequado da língua oral e da língua escrita na diversidade das situações comunicativas de que participam" (BNCC, 2017, p. 63).

Mostramos aqui a importância de um ensino pautado em atividades que se originam de um interesse real na vida dos alunos e cuja realização envolve o uso da escrita e leitura de textos que circulam na sociedade, partindo de gêneros discursivos aliados a questões do cotidiano dos educandos, prática denominada letramento. Como aponta Kleiman (2007, p. 16):

Os estudos do letramento nos mostram, e isto é muito importante para a reflexão curricular, que os eventos de letramento exigem a mobilização de diversos recursos e conhecimentos por parte dos participantes das atividades. Isso significa que alguns eventos de letramento voltados para a resolução de alguma meta da vida social criarão, sem dúvida alguma, inúmeras oportunidades de aprendizagem para os participantes, todas elas diferentes entre si, segundo as diferenças existentes entre os indivíduos participantes. Cabe ao professor destacar e sistematizar aqueles aspectos que fazem parte de seu planejamento semestral, anual ou cíclico, tantas vezes quanto forem necessárias, para o aluno adquirir confiança e autonomia com relação ao conteúdo visado. 
Para alcançarmos tal objetivo, planejamos uma atividade pedagógica interdisciplinar de Língua Portuguesa. Realizamos ainda um momento de articulação com o componente curricular de Língua Inglesa. Destacamos também aspectos pertinentes ao que preconiza a BNCC (BRASIL, 2017) para o trabalho pedagógico no último componente curricular mencionado. A atividade pedagógica aqui exemplificada poderia compor um projeto de letramento ou interdisciplinar ou, ainda, uma unidade didática, os quais funcionam como ferramentas pedagógicas contextualizadoras de práticas de linguagem (cf. SILVA, 2015).

O ensino da Língua Inglesa nas escolas brasileiras há muito tempo vem sendo alvo de críticas, pois, observando o cotidiano das salas de aula, é possível verificar que os métodos utilizados para ensinar essa língua são excessivamente prescritivos. Há uma maior preocupação, principalmente, com a decodificação, a repetição e a memorização de um conjunto de estruturas e de regras gramaticais de modo abstrato, descontextualizadas de situações enunciativas concretas, muitas vezes alheias à realidade linguística dos estudantes (cf. OLIVEIRA, 2015; LEFFA, 2016).

Entretanto, hoje, em pleno século XXI, com o novo cenário estabelecido, com o advento da internet, com o encontro das culturas, o ensino de línguas no contexto educacional deve estar vinculado ao uso. Em acordo com a proposta pedagógica bakhtiniana, recomendamos o ensino das formas da língua a partir de seu significado semântico, pragmático e estilístico, mediante os usos de enunciados concretos manifestados nos gêneros discursivos, evitando o trabalho escolarizado com a escrita (cf. BAKHTIN, 2013). Observar a língua e os enunciados em sua realidade visa contribuir para o desenvolvimento da competência comunicativa e da consciência intercultural crítica dos estudantes (cf. WIDDOWSON, 2005), assim como proposto na BNCC (BRASIL, 2017), conforme reproduzido no excerto do Exemplo 7.

\footnotetext{
Exemplo 7: BNCC - "Língua Inglesa"

"Aprender a língua inglesa propicia a criação de novas formas de engajamento e participação dos alunos em um mundo social cada vez mais globalizado e plural, em que as fronteiras entre países e interesses pessoais, locais, regionais, nacionais transnacionais estão cada vez mais difusas e contraditórias. Assim, o estudo da língua inglesa possibilita aos alunos ampliar horizontes de comunicação e de intercâmbio cultural, científico e acadêmico e, nesse sentido, abre novos percursos de acesso, construção de conhecimentos e participação social. É esse caráter formativo que inscreve a aprendizagem de inglês em uma perspectiva de educação linguística, consciente e crítica, na qual as dimensões pedagógicas e políticas são intrinsecamente ligadas" (BRASIL, 2017, p.199).
}

Conforme o Exemplo 7, tem sido cada vez mais evidente a necessidade de considerar a função social do ensino de Língua Inglesa, que, no nosso contexto, é vista sempre com o intuito principal de capacitar o aluno em sua competência linguística, algumas vezes focando mais na dimensão formal da língua, outras na competência comunicativa. No entanto, há pouca preocupação com a formação crítica do aluno como cidadão que vive, age e interage na sociedade, pressuposto presente nos esclarecimentos 
gerais da BNCC (BRASIL, 2017). Essa configuração não é muito diferente no tocante ao ensino do português como língua materna.

Sendo assim, conforme a BNCC (BRASIL, 2017), há um objetivo claro de trabalhar a função social da Língua Inglesa, para que o educando possa utilizá-la de maneira mais consciente no cotidiano, não desenvolvendo apenas habilidades de ler e escrever, mas de utilizar o texto oral, escrito ou visual para uma reflexão crítica. $\mathrm{Na}$ realidade, o aluno precisa se engajar em atividade crítica a partir da linguagem, como preconiza o documento no excerto do Exemplo 8.

\section{Exemplo 8: BNCC - "Língua inglesa no Ensino Fundamental - anos finais: unidades} temáticas, objetos de conhecimento e habilidades"

"A BNCC de Língua Inglesa procura motivar os alunos a refletir sobre a presença dessa língua estrangeira em seu cotidiano, incentivando as práticas discursivas e linguísticas. E, com base nessa reflexão, levá-los a construir um discurso próprio às suas intenções comunicativas, de modo a consolidar práticas sociais de uso. Nessa perspectiva, não é apenas o domínio das estruturas gramaticais que está em jogo, mas a possibilidade de os alunos terem o domínio de mais uma linguagem que circula socialmente. A BNCC de Língua Inglesa para o Ensino Fundamental - Anos Finais está organizada por eixos, unidades temáticas, objetos de conhecimento e habilidades, distribuídos por ano de escolaridade $\left(6^{\circ}, 7^{\circ}, 8^{\circ}\right.$ e $9^{\circ}$ anos $)$, em um crescente grau de complexidade e consolidação das aprendizagens, para facilitar a organização didática dos professores" (BRASIL, 2017, p. 203).

Como se vê, na BNCC (BRASIL 2017), o trabalho da Língua Inglesa também deve ser organizado em eixos, informados pelas quatro habilidades linguísticas: "oralidade" (escuta e fala); "leitura"; "escrita"; e pelos eixos "conhecimentos linguísticos e gramaticais" e "dimensão intercultural". No eixo "conhecimentos linguísticos e gramaticais", recomenda-se o estudo do léxico e da gramática de modo contextualizado e indutivo. Em "dimensão intercultural", compreende-se que aprender inglês implica problematizar os diferentes papeis dessa língua no mundo, seus valores e efeitos nas interações sociais, isto é, respeitar e compreender as diferenças. Embora, esses cinco eixos sejam tratados separadamente, estão intrinsicamente ligados nas práticas sociais de uso da língua.

Na nossa visão, portanto, as propostas da BNCC (BRASIL, 2017), de alguma forma, vêm ao encontro da visão de língua como um construto social, uma vez que leva em conta a compreensão da finalidade do ensino da língua para que este processo passe a fazer sentido na escola, assumindo o seu verdadeiro valor educativo, que vai muito além de simplesmente capacitar o aluno a conhecer o funcionamento gramatical da língua alvo.

\section{PROPOSTA DE ATIVIDADE PEDAGÓGICA}

Em resposta às demandas pontuadas nos escritos docentes, propomos uma atividade pedagógica interdisciplinar de modo a levar o educando a pensar sobre os 
fenômenos que envolvem a linguagem, sem se preocupar inicialmente com nomenclaturas. $\mathrm{Na}$ abordagem dos estudos do letramento linguístico, enfocamos o estudo da língua numa perspectiva funcional.

Por interdisciplinaridade, compreendemos um trabalho pedagógico que envolve convergência, cruzamento e descentralização de disciplinas escolares, em função do estabelecimento e manutenção do dinamismo, nas atividades escolares (cf. POMBO, 2006). A interdisciplinaridade se materializa pela integração das diferentes áreas do conhecimento, em um trabalho de cooperação, procurando superar a fragmentação do currículo escolar.

Segundo Luck (1994), o objetivo da interdisciplinaridade é, portanto, o de promover a superação da visão restrita de mundo e a compreensão da complexidade da realidade, ao mesmo tempo resgatando a centralidade do homem no contidiano e na produção do conhecimento, de modo a permitir uma melhor compreensão da realidade e do homem como o ser determinante e determinado. Desse modo, a partir de atividades interdisciplinares, torna-se possível transformar o conhecimento em algo útil que interligue conteúdos programados e realidade. É preciso romper com a ideia de uma prática pedagógica baseada em disciplinas estanques, conforme expressaram as próprias professoras envolvidas nesta pesquisa.

No Quadro 2, reproduzimos os objetos de conhecimentos apresentados na BNCC (BRASIL, 2017) e selecionados para a elaboração da atividade pedagógica. O eixo de "conhecimentos linguísticos e gramaticais" foi focalizado diretamente em Língua Portuguesa e em Língua Inglesa, para turma do $9^{\circ}$ ano.

\section{LÍNGUA PORTUGUESA $-9^{\circ}$ ano}

"CONHECIMENTOS LINGUÍSTICOS E GRAMATICAIS - Práticas de análise linguística e gramatical (como estratégia para o desenvolvimento produtivo das práticas de oralidade, leitura e escrita). Reflexão sobre os usos do léxico e de regularidades no funcionamento da língua falada e escrita".

\begin{tabular}{l|l|l}
\hline \multicolumn{1}{c|}{ UNIDADE } & \multicolumn{1}{|c}{ OBJETO DE } \\
TEMÁTICA & CONHECIMENTO & \multicolumn{1}{c}{ HABILIDADES } \\
\hline "Variação & "Variedades & "(EF09LP27) Reconhecer as variedades da \\
linguísticas e norma & $\begin{array}{l}\text { língua falada, o conceito de norma-padrão e } \\
\text { padrão" } \\
\text { o de preconceito linguístico"4. } \\
\text { "(EF09LP28) Fazer uso consciente e } \\
\text { reflexivo de regras e normas da norma- } \\
\text { padrão em situações de fala e escrita nas quais } \\
\text { ela deve ser usada". }\end{array}$ \\
\hline
\end{tabular}

LÍNGUA INGLESA $-9^{\circ}$ ano

${ }^{4}$ Esse código alfanumérico é utilizado para identificar cada habilidade apresentada nos diferentes "componentes curriculares": EF = Ensino Fundamental; $09=9^{\circ}$ ano; LP = Língua Portuguesa; $27=$ número da habilidade na sequência elencada para cada "componente curricular". 
"EIXO CONHECIMENTOS LINGUÍSTICOS E GRAMATICAIS - Práticas de análise linguística e gramatical para a reflexão sobre as regularidades e irregularidades da língua inglesa, com base nos usos de linguagem trabalhados nos eixos Oralidade, Leitura, Escrita e Dimensão intercultural".

\begin{tabular}{c|l|l}
\hline UNIDADE & \multicolumn{2}{|c}{ OBJETO DE } \\
TEMÁTICA & CONHECIMENTO & \multicolumn{1}{c}{ HABILIDADE } \\
\hline "Estudo do léxico" & $\begin{array}{l}\text { "Usos de linguagem } \\
\text { em meio digital: } \\
\text { 'internetês" }\end{array}$ & $\begin{array}{l}\text { "(EF09LI13) Reconhecer, nos novos } \\
\text { gêneros digitais (blogues, mensagens } \\
\text { instantâneas, tweets, entre outros), novas } \\
\text { formas de escrita (abreviação de palavras, } \\
\text { palavras com combinação de letras e } \\
\text { números, pictogramas, símbolos gráficos, } \\
\text { entre outros) na constituição das } \\
\text { mensagens". }\end{array}$ \\
\hline
\end{tabular}

Quadro 2: "Objetos de conhecimento" selecionados em LP e LI (9 Ano)

Fonte: BNCC (BRASIL, 2017, p. 147 / 218-219)

Com intuito de fomentar os estudos das práticas linguísticas, criamos uma atividade sob um olhar epilinguístico, que, na escola, "é defendida como uma prática estimulada e consciente da linguagem, com variação dos recursos expressivos e formais como meio de obter novos efeitos de sentido" (SILVA, 2011, p. 29). Objetivamos propiciar, de forma dinâmica e criativa, o estudo da variedade linguística presente atualmente na web, o internetês. Abordamos esse tema por ser descrito como uma "forma grafolinguística" utilizada tipicamente em textos encontrados em chats, blogs e outros mecanismos mediadores de redes sociais (KOMESU; TENANI, 2009).

Em Língua Portuguesa, escolhemos o "objeto de conhecimento" variedades linguísticas para levar o aluno a refletir sobre a dinamicidade da língua, refletir sobre as transformações que a sociedade vem sofrendo com o advento da internet e de algumas tecnologias digitais. Essas transformações tecnológicas afetam diretamente a maneira como nos comunicamos. Formas de interação diferenciadas surgiram, gêneros discursivos diferenciados emergiram para atender às demandas do atual contexto cultural. Assim, uma das missões da professora de Língua Portuguesa "é transformar seu aluno num poliglota dentro de sua própria língua, possibilitando-lhe escolher a língua funcional adequada a cada momento" (BECHARA, 1998, p. 14).

Em Língua Inglesa, trabalhamos com o "objeto de conhecimento" proposto para o mesmo nível de escolaridade da escolha para o "componente curricular" destacado no parágrafo anterior: "usos de linguagem em meio digital". Em outras palavras, a escolha de conteúdos elencados para o mesmo ano de escolaridade se justifica pela proposição de atividades pedagógicas a partir do diálogo de duas disciplinas escolares.

A atividade pedagógica elaborada pelas professoras e selecionada para este artigo está organizada em três momentos: compreensão textual; texto e cotidiano; e língua inglesa e comunicação na internet. No primeiro, são proposta questões de interpretação do conteúdo tematizado no texto selecionado. No segundo, são propostas questões que 
possibilitam aos alunos refletirem sobre o conteúdo tematizado no texto e algumas situações interativas culturalmente moldadas fora do domínio escolar. No terceiro momento, são focalizadas algumas interferências da tecnologia digital, utilizada para comunicação, em usos da língua inglesa.

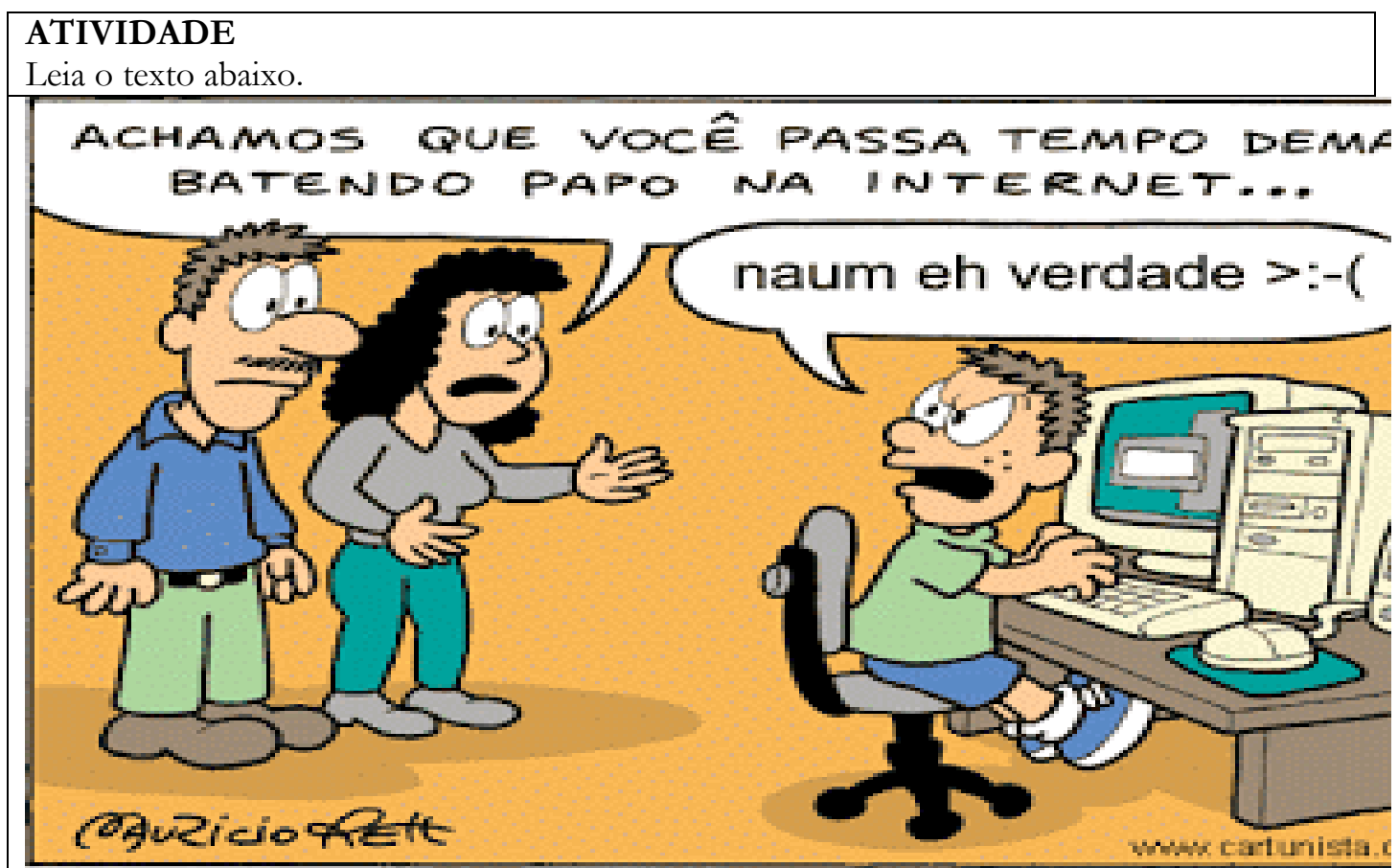

Fonte: < http://pibidletrasurca.blogspot.com.br/2012/06/charges-sobre-internetes-material.html> acesso em 10 de junho de 2017.

\section{PARTE 1: COMPREENSÃO TEXTUAL}

Conforme o texto lido, responda as seguintes questões:

1. Qual é o assunto discutido no texto?

Resposta sugerida: $O$ assunto discutido no texto é o uso excessivo da internet e das redes sociais.

2. Pelo discurso proferido pelo casal, podemos deduzir que o grau de parentesco dos falantes é bem próximo. Qual seria o parentesco? Levante hipóteses.

Resposta sugerida: Observando o discurso proferido pelo casal, podemos deduzir que, provavelmente, os falantes são os pais ou tios do garoto.

3. Reconheça, no texto, palavras que não são oficiais da norma padrão da língua portuguesa. Resposta sugerida: naum, eh.

4. Onde a linguagem empregada pelo garoto é utilizada?

Resposta sugerida: A linguagem empregada pelo garoto é utilizada na internet, especialmente em e-mails informais, bate-papos e redes sociais. 
5. Considerando a resposta do jovem, o que teria motivado a forma como a resposta foi dada? Resposta sugerida: De acordo com a resposta dada pelo jovem, nota-se que ele realmente passa muito tempo na internet. A representação da fala foi realizada com a escrita utilizada em interações na internet.

6. A variedade da língua representada na fala do jovem é utilizada efetivamente na oralidade? Resposta sugerida: Espera-se que o aluno perceba que não. Na fala não é possivel identificar as modificações desse tipo de variedade, pois é característica da linguagem verbal escrita utilizada na internet.

7. O casal tem razões para se preocupar com o tempo que o jovem passa usando o computador? Resposta sugerida: Espera-se que o aluno responda que sim, visto que a suspeita é confirmada pela resposta dada pelo garoto, ou seja, denuncia o uso excessivo da internet.

8. Nos textos que circulam na web, é comum utilizarem os sinais de pontuação para expressar emoções. Localize no texto um exemplo. Que nome é dado a esse tipo de expressão. E no contexto, o que ela significa?

Resposta sugerida: O nome dado a esse tipo de expressão é "emoticons". No texto foi utilizado o símbolo >:-( que significa chateado, inconformado.

\section{PARTE 2: TEXTO E COTIDIANO}

1. Quando você usa as redes sociais para se comunicar, qual é o tipo de variedade da língua utilizada (formal ou informal)? Por quê?

Resposta sugerida: Espera-se que aluno conclua que a variedade escolbida depende do contexto, finalidade e interlocutor.

2. Você sabe qual é o nome dado a essa nova forma de se comunicar, utilizada na internet, usando palavras abreviadas, símbolos, suprimindo vogais e acentos?

Resposta sugerida: Essa nova forma de se comunicar, utilizada na internet, é chamada de internetês.

3. Em quais das situações descritas abaixo, é adequada a utilização do internetês, ou seja, da variedade escrita característica nos ambientes interativos digitais?

(A) E-mail para o amigo.

(B) E-mail para o chefe.

(C) Convite informal pelo celular para um primo.

(D) Carta de apresentação curricular para uma empresa.

(E) Mensagem pelo Whatsapp para um colega, justificando sua ausência na escola.

(F) Mensagem pelo Whatsapp para a coordenadora ou diretora, justificando sua ausência na escola.

Respostas sugeridas: Alternativas: (A), (C) e (E).

4. Esse fenômeno linguístico, influenciado pela interação mediada por aparelhos digitais, só ocorre na língua portuguesa ou pode ocorrer também em outras línguas?

Resposta sugerida: Espera-se que o aluno compreenda a dinamicidade da lingua e responda que qualquer língua está passivel ao tipo de variação linguística focalizada.

5. Que significados você atribui às carinhas ou emoticons reproduzidos adiante? 


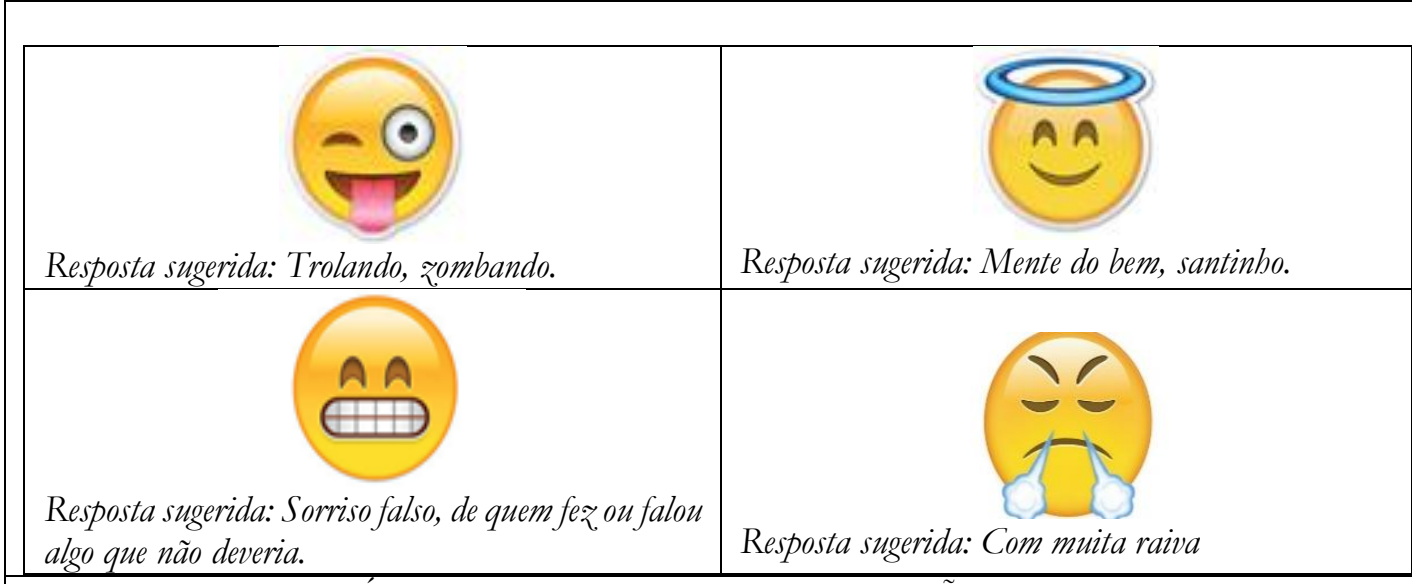

\section{PARTE 3: LÍNGUA INGLESA E COMUNICAÇÃO NA INTERNET}

1. Faça uma pesquisa e registre pelo menos 05 exemplos de formas linguísticas diferenciadas de uso da língua inglesa na internet.

Resposta sugerida: A resposta será formulada a partir de pesquisa. Seguem alguns exemplos:

Cause - "Because" (porque)

LOL - "Laughing Out Loud" - (Rir às gargalhadas)

$A S A P$ - "As soon as possible" - (Assim que possivel)

WTH - "What the hell" - (Que inferno!)

$H \& K$ - "Hugs and Kisses" - (Abracos e beijos!)

2. Complete a cruzadinha abaixo com os nomes de algumas das mídias sociais mais usadas no Brasil.

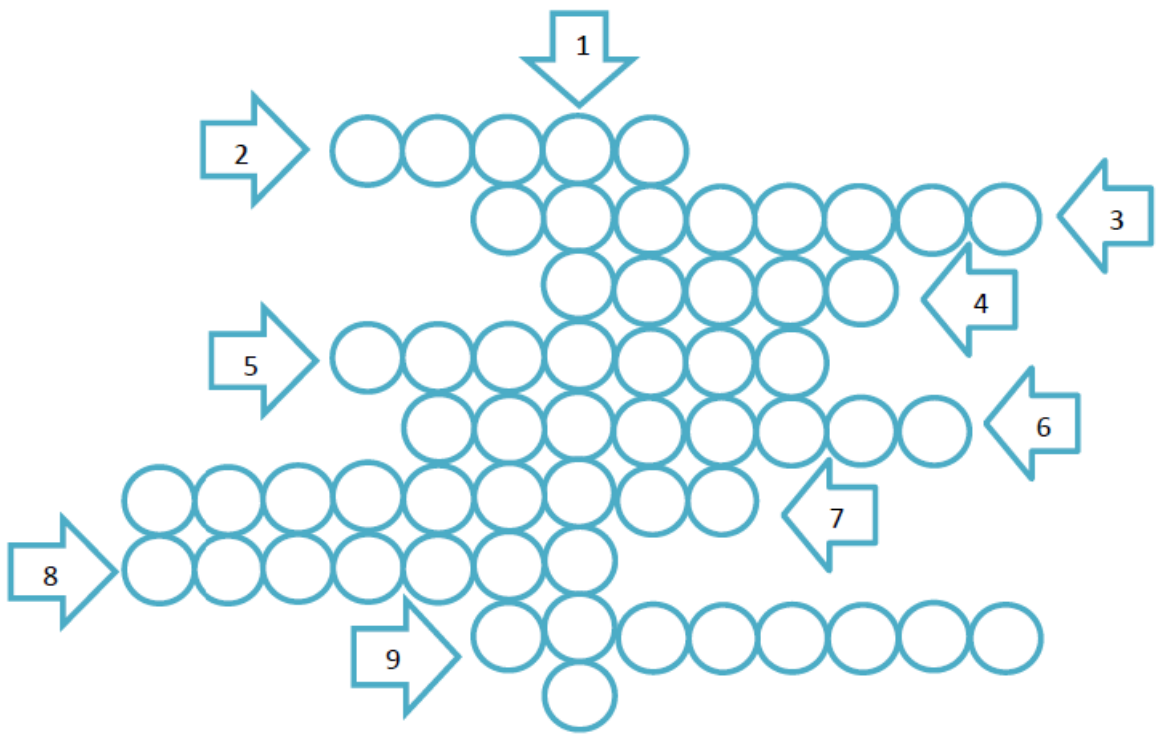


1) É uma rede social usada normalmente para a postagem de fotos para usuários de Androide iPhone.

2) Correio eletrônico que permite produzir, enviar e receber mensagens através de sistema eletrônico de comunicação.

3) Aplicativo de troca de mensagens. O foco é a troca dos famosos snaps, fotos e vídeos instantâneos que desaparecem após alguns segundos.

4) É um aplicativo que possibilita aos usuários tirar fotos, gravar vídeos, adicionar textos e desenhos à imagem e, ainda, possibilita comunicações de voz e vídeo via internet, permitindo ligação gratuita entre os usuários.

5) É um dos sites mais acessados no Brasil, possibilita aos usuários o envio de vídeos para serem compartilhados na rede.

6) Aplicativo de mensagens para smartphones mais utilizado atualmente.

7) Separou-se do Facebook. É usado por celulares que contém Android, é um dos aplicativos mais usado pelos brasileiros assim como Whatsapp.

8) É uma rede social que permite aos usuários enviar e receber atualizações pessoais de outros contatos, exibidas no perfil de um usuário em tempo real, tem perfil que atende a outros usuários seguidores de pessoas de seu interesse.

9) É considerada uma das maiores redes sociais do mundo. Muito comum entre os jovens brasileiros. Os usuários criam perfis que contêm fotos e listas de interesses pessoais, muito interativo e dinâmico.

Respostas sugeridas:

1 -Instagram 2-Email 3-Snapchat 4-Skype 5-You tube 6-Whatsapp

7 -Messenger 8-Twitter 9-Facebook.

3. Que relação há entre os nomes da maioria das mídias sociais e a língua inglesa?

Resposta sugerida: Os nomes dos aplicativos e redes sociais mais usadas no mundo inteiro são escritos em inglês. A escolba do nome em lingua inglesa contribui para propagar a identidade do produto, uma vez que a referida lingua é reconhecida mundialmente. Essa escolha revela a hegemonia do inglês e também de certos países falantes do inglês, os quais detêm o dominio da tecnologia criada.

Com a atividade pedagógica proposta, as professoras pretenderam trabalhar com os alunos a noção variedades de uso da língua, motivadas pela produção de tecnologias digitais. O propósito é que os alunos compreendam as variações no uso da língua como um fenômeno comum às línguas ${ }^{5}$. Como é sabido, as línguas não param de mudar, estão em constante transformação. São influenciadas por diferentes linguagens e, inclusive, pelo desenvolvimento tecnológico. É possível criar palavras novas ou tomar palavras emprestadas em outras línguas. Em português brasileiro, existe um grande número de

\footnotetext{
5 A título de ilustração, na língua inglesa, podemos citar alguns exemplos de variedade/diversidade dos vários ingleses falados no mundo - Singlish (Cingapura), Franglais (França), Hinglish (Índia), Denglish (Alemanha), entre outros. Esses casos não correspondem a variedades motivadas por usos das tecnologias digitais.
} 
palavras originárias de empréstimos de muitas outras línguas, inclusive do inglês (estrangeirismos).

Propomos levar os alunos a observarem esse fenômeno tanto na língua portuguesa quanto na língua inglesa de modo que eles possam aprender a integrar a linguagem da internet ao contexto das variedades da língua, fazendo adequações entre a norma linguística e o uso da língua em contextos reais. Assim, os aprendizes perceberão o encontro de culturas, a dinâmica característica das línguas, podendo desenvolver a competência comunicativa e a consciência intercultural.

\section{CONSIDERAÇÕES FINAIS}

Este artigo possibilitou o registro de uma experiência de formação continuada de professoras, mediada pela pesquisa. Em contextos de instrução formal, a exemplo do mestrado profissional para educadores, certamente, a familiarização das professoras com o percurso de produção do conhecimento deve ser a lição mais produtiva, pois algumas investigações científicas já mostraram que a reprodução de conhecimentos teóricos, produzidos na universidade, não garante as transformações esperadas para as salas de aula do ensino básico (cf. SILVA, 2016; 2017). Os conhecimentos produzidos pelas professoras, sob a mediação do formador, contribuíram minimamente para: (1) a produção de reflexões necessárias à teorização da formação continuada; e (2) a familiarização das professoras com práticas de produção de material didático.

Nesse sentido, a metodologia de ensino utilizada no mestrado profissional se mostrou relevante para empoderar as professoras, uma vez que elas passaram a exercer a função de produtoras das atividades pedagógicas, deslocando-se da função de meras usuárias de livros didáticos, por exemplo. A prática experienciada pelas professoras pode contribuir para a construção da autonomia necessária para fazer adaptações ou transformações em materiais didáticos de diferentes origens, não produzidos pelas próprias profissionais e, portanto, não completamente adequados para os diferentes contextos de trabalho do professor.

Por fim, destacamos a importância da interdisciplinaridade na promoção de um letramento mais produtivo, menos escolarizado, para que o aluno do ensino básico, realmente, apreenda algum sentido nos "objetos de conhecimento" trabalhados em sala de aula. A interdisciplinaridade contribui para romper com o ensino da língua baseado apenas na dimensão formal dos sistemas linguísticos, possibilita o trabalho pedagógico com diferentes linguagens, em função de diversas situações interativas que, como cidadãos, deparamo-nos diariamente. 


\section{REFERENNCIAS}

BAKHTIN, M. M. Questões de estilística no ensino da língua. In: Questões de estilística no ensino da lingua: Mikhhail Bakbtin. Tradução, posfácio e notas de Sheila Grillo e Ekaterina Vólkova Américo. São Paulo: Editora 34, 2013. p. 23 - 43.

BARTON, D.; HAMILTON, M. Local Literacies: Reading and Writing in One Community. London: Routledge, 2012.

BECHARA, E. Ensino da gramática. Opressão? Liberdade? 10ª edição. São Paulo: Ática, 1998.

BRASIL. Ministério da Educação. Base Nacional Comum Curricular. Proposta preliminar. Terceira versão revista. Brasília: MEC, 2016. Disponível em: $<$ http://basenacionalcomum.mec.gov.br /documentos/bncc-2versao.revista.pdf $>$. Acesso em: 23 mar. 2017.

KLEIMAN, A. Letramento e suas implicações para o ensino de língua materna. Revista Signo. Santa Cruz do Sul: UNISC, v. 32 n. 53, p. 1-25, 2007.

KLEIMAN, A. Modelos de letramento e as práticas de alfabetização na escola. In: KLEIMAN, A. (Org.). Os significados do letramento: uma nova perspectiva sobre a prática social da escrita. Campinas: Mercado de Letras, 1995, p. 15 - 61.

KOMESU, F.; TENANI, L. Considerações sobre o conceito de "internetês" nos estudos da linguagem. Linguagem em (Dis)curso. Palhoça: UNISUL, v. 9, n. 3, p. 621 - 643, 2009.

LEFFA, V. J. Lingua estrangeira: ensino e aprendizagem. Pelotas: EDUCAT, 2016.

LUCK, H. Pedagogia Interdisciplinar: Fundamentos Teóricos e Metodológicos. Petrópolis: Vozes, 1994.

OLIVEIRA, L. A. Aula de Inglês: do planejamento à avaliação. São Paulo: Parábola Editorial, 2015.

PAULIOKONIS, A. L.; MARQUESI, S. C.; ELIAS, V. M. Linguística textual e ensino. São Paulo: Contexto, 2017

POMBO, O. Práticas interdisciplinares. Sociologias. Porto Alegre: UFRGS, ano 8, n. 15, p. 208-249, 2006.

SILVA, W. R. Estudo da gramática no texto: demandas para o ensino e a formação do professor de lingua materna. Maringá: Eduem, 2011.

- Gêneros em práticas escolares de linguagens: currículo e formação do professor. Revista Brasileira de Linguistica Aplicada. Belo Horizonte: UFMG, v. 15, n. 4, p. 1023-1055, 2015.

- Fortalecimento de letramentos de professoras: um estudo no Mestrado Profissional em Letras. Letras \& Letras. Uberlândia: UFU, v. 32, n. 2, p. 314-337, 2016. 
. Formação sustentável do professor no mestrado profissional. Revista Brasileira de Educação. Rio de Janeiro: Anped, v. 22, n. 70, p. 708-731, 2017.

; Sousa, W. B.; Araújo, S. F. De C. Construção de saberes no Mestrado Profissional em Letras: uma experiência compartilhada. Leia escola. Campinas Grande: UFCG, v. 17, n. 1, p. 32-44, 2017.

; GUIMARÃES, E. V.; MEDEIROS, I. A. Construção de objetos de conhecimento para aulas de Língua Portuguesa na abordagem do letramento científico. Revista Brasileira de Linguística Aplicada. Belo Horizonte: UFMG. 2018 (no prelo).

SOARES, M. Letramento e alfabetização: as muitas facetas. Revista Brasileira de Educação. Rio de Janeiro: Anped, n. 25, p. 5-17, 2004.

- Alfabetização: a questão dos métodos. São Paulo: Contexto, 2016.

STREET, B. V. Letramentos sociais: abordagens críticas do letramento no desenvolvimento, na etnografia e na educação. Trad.: Marcos Bagno. São Paulo: Parábola Editorial, 2014.

WIDDOWSON, H. G. O ensino de línguas para a comunicação. Tradução de José Carlos P. de Almeida Filho. Campinas, SP: Pontes, 2. ed. 2005.

\section{AGRADECIMENTO}

Agradecemos as contribuições dos pareceristas anônimos deste artigo, as possíveis fragilidades restantes neste texto, porém, são da nossa completa responsabilidade. O primeiro autor deste artigo agradece ao Conselho Nacional de Desenvolvimento Científico e Tecnológico (CNPq) pela bolsa de produtividade em pesquisa (PQ-2) concedida, contribuindo portanto para produção da pesquisa apresentada neste artigo (Processo 305094/2016-5). 